\title{
O RITO E OS EMBLEMAS NA FORMATURA DAS ENFERMEIRAS BRASILEIRAS NO DISTRITO FEDERAL (1924-1925)
}

\author{
The rite and emblems at the graduation of brazilian \\ nurses in the federal district in brazil (1924-1925)
El rito y los emblemas en la formatura de las enfermeras brasileñas en la capital federal (1924-1925)

Fernando Porto

Tânia Cristina Franco Santos²

\section{RESUMO}

Estudo histórico-social com o objetivo de analisar a formatura das escolas de enfermagem, em relação ao seu significado e aos emblemas como efeito da assinatura imagética das escolas e da profissão enfermagem para a sociedade. A análise do corpus documental se fez a partir da contextualização das fotografias, com base nos documentos escritos. 0 estudo evidenciou que os ritos de formaturas foi uma das maneiras de publicar a imagem da enfermeira à época, e que as representações objetais foram marcas emblemáticas na produção da crença simbólica. Desse modo, podemos ao final considerar que os ritos institucionais e as reapresentações objetais utilizados pela Escola Prática de Enfermeiras da Cruz Vermelha Brasileira e da Escola de Enfermeiras do Departamento Nacional de Saúde Pública foram estratégias de proclamarem a identidade da profissão, cada qual a sua maneira.

Palavras-chave: Enfermagem. História da Enfermagem. Comportamento Ritualístico.

\begin{abstract}
Socio-historical study aiming to examine the graduation of Nursing schools regarding its meaning and the emblems as an effect to fix the image of schools and the nursing profession to society. The analysis of the documentary Corpus was made from the context of photographs, based on written documents. The study showed that the graduation rites were one of the ways to publish the image of the nurse at that time and the objects representations were flagship brands in the production of symbolic beliefs. Thus, it is possible to finally consider that the institutional rites and objects representations used by the Practical School of Nurses of the Brazilian Red Cross and the School of Nurses of the National Department of Public Health were strategies to proclaim the Identity of the profession in their own ways.
\end{abstract}

Keywords: Nursing. History of nursing. Ritualistic behavior

\section{Resumen}

Estudio histórico social con el objetivo de analizar la graduación de las escuelas de enfermería, en cuanto a su significado y a los emblemas como efecto de la fijación de la imagen de las escuelas y de la profesión enfermería a la sociedad. El análisis del corpus documental se hizo a partir del contexto de las fotografías, con base en los documentos escritos. El estudio evidenció que los ritos de formatura fue una de las maneras de publicar la imagen de la enfermera a la época, y las representaciones de los objetos fueron marcas evidentes en la producción de la creencia simbólica. Así, podemos al final considerar que los ritos institucionales y las reexhibiciones de los objetos utilizados por la "Escola Prática de Enfermeiras da Cruz Vermelha Brasileira" y por la "Escola de Enfermeiras do Departamento Nacional de Saúde Pública" fueron estrategias a que proclamaran la identidad de la profesión cada cual a su manera.

Palabras clave: Enfermería. Historia de la enfermería. Comportamiento del ritual.

'Doutor em enfermagem. Professor Adjunto da Escola de Enfermagem Alfredo Pinto/UNIRIO. Membro dos grupos de pesquisa LAPHE/EEAP/ UNIRIO e NUPPHEBRAS/EEAN/UFRJ. Brasil. E-mail: ramosporto@opelink.com.br, ${ }^{2}$ Doutora em Enfermagem. Professora Adjunta da Escola de Enfermagem Anna Nery, Membro do grupo de pesquisa NUPHEBRAS/EEAN/UFRJ e bolsista de estágio pós-doutoral no exterior pela Capes. Brasil. E-mail:taniacristinafsc@terra.com.br 


\section{CONSIDERAÇÕES INICIAIS}

0 presente estudo é um recorte da tese de doutorado intitulada $O s$ ritos institucionais e a imagem pública da enfermeira brasileira na imprensa ilustrada: o poder simbólico no click fotográfico (1919-1925). A formatura foi e é um rito institucional promovido pelas escolas de Enfermagem ao término do curso. A primeira formatura de enfermeiros no Rio de Janeiro, pelo que se sabe por meio de diversos estudos da história da Enfermagem, ocorreu pela Escola Profissional de Enfermeiros e Enfermeiras da Assistência a Alienados, em 1906, com destaque na imprensa escrita do Jornal do Commercio e o País ${ }^{1}$.

Entre os anos de 1916 e 1925, três escolas de Enfermagem no Distrito Federal formaram enfermeiras para o país: a Escola Prática de Enfermeiras da Cruz Vermelha Brasileira, criada em 1916; a Escola Profissional de Enfermeiros e Enfermeiras da Assistência a Alienados (1890), desdobrada oficialmente em 1920 e em 1921 intitulada Escola Profissional de Enfermeiras Alfredo Pinto, atual Escola de Enfermagem Alfredo Pinto da Universidade Federal do Estado do Rio de Janeiro; e a Escola de Enfermeiras do Departamento Nacional de Saúde Pública criada em 1922, atual Escola de Enfermagem Anna Nery da Universidade Federal do Rio de Janeiro.

Essas escolas constituíram pauta, por meio do rito de formatura de enfermeiras, na imprensa escrita, por exemplo, em 1917, a Escola Prática de Enfermeiras da Cruz Vermelha Brasileira (RJ), no jornal Gazeta de Notícias²; em 1921, a Escola Profissional de Enfermeiras Alfredo Pinto, nos jornais denominados Jornal do Commercio, o Jornal e o País; e em 1925, a Escola e Enfermeiras do Departamento Nacional de Saúde Pública no Jornal do Brasili.

As notícias veiculadas por esse meio de comunicação se referiam às formaturas das turmas de cada escola de Enfermagem à época, articulando texto escrito e fotográfico, em alguns dos registros jornalísticos destinados à população em geral.

A imprensa ilustrada, especialmente a Revista da Semana, era destinada às mulheres. Essa revista apresentava temas contemporâneos, excluindo aqueles relativos a políticos e assuntos escandalosos, com destaque para apresentação majoritária de fotografias, propiciando uma leitura leve para as mulheres ${ }^{3}$.

No período de 1924 a 1925, as enfermeiras formadas pelas escolas de Enfermagem foram mira do click fotográfico da imprensa ilustrada. 0 rito institucional de formatura da Escola Prática de Enfermeiras da Cruz Vermelha Brasileira (1924) e da Escola de Enfermeiras do Departamento Nacional de Saúde Pública (1925) foi veiculado na Revista da Semana.

Diante do exposto, partimos da premissa de que o rito institucional de formatura de enfermeiras, ao ser veiculado na Revista da Semana, contribuiu como estratégia de publicação da boa imagem da enfermeira para a sociedade brasileira.
0 estudo tem por objetivo analisar a formatura das escolas de Enfermagem, em relação ao seu significado e às representações objetais como efeito da assinatura imagética das instituições e da profissão enfermagem para a sociedade.

\section{ASPECTO METODOLÓGICO E TEÓRICO}

A abordagem adotada no estudo foi a histórico-social, por meio dos documentos escritos e fotográficos. Os documentos escritos foram o histórico da Cruz Vermelha Brasileira e a revista Brazil-Médico. As fotos analisadas foram publicadas na Revista da Semana e totalizaram três, tendo como critério a aderência ao foco do estudo sobre as formaturas da Escola Prática de Enfermeiras da Cruz Vermelha Brasileira e da Escola de Enfermeiras do Departamento Nacional de Saúde Pública, no período de 1924 a 1925.

Para analisar as fotos, foi aplicada uma matriz dividida em quatro partes. A primeira parte pretendeu identificar a publicação quanto ao ano, número da revista, página e data; a segunda e a terceira, dados sobre o plano de expressão e conteúdo, por meio dos conceitos da semiótica; e a quarta, dados de articulação com a imagem analisada. Ademais, foram utilizados para análise das fotos os elementos da linguagem não-verbal (proxêmica), como forma de comunicação, a expressão facial e corporal (cinésica) e os atributos pessoais e de paisagem (linguagem paraverbal), quando articulados aos documentos escritos ${ }^{3}$.

Nesse sentido, as fotos foram contextualizadas com fontes secundárias oriundas de artigos, dissertações e teses de aproximação com o objeto de estudo. A interpretação dos dados se pautou em três conceitos-chave para o estudo: rito institucional, representação objetal e hexis corporal, do sociólogo francês Pierre Bourdieu.

0 fenômeno da formatura como rito institucional se entendeu como um ato de comunicação, quer no sentido de sua expressão, quer na notificação, com autoridade, de que alguém ou algo é o que deve ser, tendo como efeito simbólico a consignação estatutária instituída na presença de uma autoridade $^{4}$. Esse rito notificava à sociedade, por meio da imagem fotográfica veiculada na imprensa ilustrada, a formação da identidade da enfermeira brasileira.

Emblemas como touca, símbolo da cruz e uniformes foram entendidos como representações objetais. Estes signos externos ao corpo e a eles associados (posturas e poses) constroem imagens próprias de seus portadores ${ }^{4}$. Assim, o texto fotográfico, veiculado na Revista da Semana sobre as formaturas de enfermeiras, foi constituído de um sistema de significações códigos -, que mereceu deferência para sua decodificação. Em outras palavras, as representações objetais ostentadas pelos corpos das enfermeiras de cada escola de enfermeira tiveram sua marca simbólica, entendida como assinatura imagética. 


\section{RESULTADOS E DISCUSSÃO}

\section{A formatura das enfermeiras}

As formaturas ocorridas nos anos de 1924 e 1925 aglutinaram alguns efeitos das comemorações do I Centenário de Independência do Brasil no contexto da Reforma Sanitária, liderada por Carlos Chagas. Esse evento foi realizado em 1922; de sua programação destacamos o Congresso Nacional dos Práticos ${ }^{3,5}$.

0 evento era composto de várias arenas de debate, entre elas médicos versus enfermeiras-visitadoras, e apesar de ser majoritariamente do gênero masculino, teve a participação da enfermeira norte-americana Ethel Parsons. Parsons foi a responsável pela confecção do relatório "As Enfermeiras de Saúde Pública" com o objetivo de mudar o conceito que a sociedade fazia da enfermeira. Sendo assim, sua estratégia foi pautada com base na racionalidade do trabalho, na padronização de condutas e nas atitudes da enfermeira em relação à sociedade ${ }^{3,5}$.

A preocupação de Parsons, ao ser analisada, era a de reconfigurar a imagem mental da enfermeira, que era associada à distribuição de esmolas e/ou a serviços de camareira. As associações tinham articulação direta com algumas das atividades das enfermeiras da Escola Prática de Enfermeiras da Cruz Vermelha Brasileira (RJ) e da Escola Profissional de Enfermeiras Alfredo Pinto. A proposta de imagem para a enfermeira de saúde pública feita por Parsons era a de que a entendessem como reformadora social ${ }^{3,5}$.

Dessa forma, o Congresso Nacional dos Práticos foi uma estratégia da corporação médica no sentido de delimitar o campo de atuação e garantir a soberania e a autoridade do poder médico ${ }^{3,5}$. Para a enfermagem, o efeito simbólico foi que o evento possibilitou a enunciação da Enfermagem moderna com a criação da Escola de Enfermeiras do Departamento Nacional de Saúde Pública, responsável pela implantação do ensino de enfermagem norte-americano no país, subvencionada pela Fundação Rockefeller.

A primeira formatura, em ordem cronológica, veiculada na Revista da Semana, foi da Escola Prática de Enfermeiras da Cruz Vermelha Brasileira, em 1924, que tinha como diretor o médico e militar Getúlio dos Santos 6 . Essa formatura ocorreu no pátio externo da instituição, na presença de autoridades, por ocasião da doação pela Sociedade da Cruz Vermelha Americana de um aparelho de raios $X$ e da comemoração do décimo sexto aniversário de criação da Cruz Vermelha no Brasil (1908-1924), que atraiu o olhar dos repórteres à época ${ }^{3,5}$.

Cabe ressaltar que o título da reportagem jornalística "Na Cruz Vermelha Brasileira" (7) não se referia à formatura das enfermeiras. A fotorreportagem apresentava um pequeno texto de algumas linhas e mais cinco fotografias. As fotografias eram todas temáticas voltadas para a formatura das enfermeiras ${ }^{3}$.

A formatura da Escola de Enfermeiras do Departamento Nacional de Saúde Pública, em 1925, ocorreu no Instituto
Nacional de Música e teve repercussão na imprensa escrita e ilustrada como um evento de monta em virtude da presença de autoridades, como a da diretora da instituição Claire Louise Kieninger ${ }^{3}$. Era o início da substituição das visitadoras de higiene por enfermeiras de saúde pública na atividade prioritária da Reforma Sanitária - o combate contra a tuberculose.

As visitadoras de higiene eram oriundas do Curso de Emergência, que foi criado em 1922; inicialmente tinha a duração de seis meses, mas ocorreu até o ano de 1924 com duração de dez meses. A criação do Curso de Emergência foi uma estratégia de tentar sanar algumas dificuldades no combate à tuberculose até que a primeira turma de enfermeiras de saúde pública estivesse formada ${ }^{3}$

Destaco que também ocorria na Cruz Vermelha Brasileira, em 1922, um Curso de Visitadoras de Higiene, pelo médico Amaury de Medeiros $^{8}$. 0 produto dessa realização não foi considerado adequado para a situação vigente pelos médicos do Departamento Nacional de Saúde Pública. Por outro lado, foi possível encontrar registro da formação, de pelo menos uma turma, de visitadoras de higiene pela Cruz Vermelha Brasileira ${ }^{6}$.

Neste sentido, a formatura da primeira turma de enfermeiras de saúde pública, ocorrida em 1925, foi publicada na Revista da Semana, ao tratar de um marco de posicionamento das enfermeiras de saúde pública no campo da saúde e ao proclamar a formação da identidade profissional após a defesa da enfermeira norte-americana Ethel Parsons no Congresso Nacional dos Práticos (1922).

\section{O significado do rito e suas representações objetais}

As formaturas das enfermeiras de ambas as escolas de Enfermagem apresentaram certas semelhanças em alguns momentos, e inovações em outros. A presença de autoridade foi uma das semelhanças entre as formaturas.

No rito de formatura da Escola Prática de Enfermeiras da Cruz Vermelha Brasileira, as fotografias e suas legendas veiculadas na Revista da Semana evidenciaram a presença de diversas autoridades, como o diretor da escola, Dr. Getulio dos Santos, o professor da escola e médico Estelita Lins, a Sra. Condessa Souza e seu esposo, o embaixador?

0 mesmo ocorreu no rito de formatura da Escola de Enfermeiras do Departamento Nacional de Saúde Pública, com a presença de algumas autoridades, como o ministro da Justiça, Dr. Affonso Pena Júnior; o embaixador dos Estados Unidos, Sr. Edwin Morgan; o diretor do Departamento Nacional de Saúde Pública, Dr. Carlos Chagas; 0 arcebispo do Rio de Janeiro, Dom Sebastião Leme; a diretora da escola de enfermeiras, Claire Louise Kieninger, e a superintendente do Serviço de Enfermeira do Departamento Nacional de Saúde Pública, a enfermeira norte-americana Ethel Parsons ${ }^{3,9}$.

A presença de autoridades nos ritos de formatura das escolas de enfermeiras se justificava pela legitimação do poder instituído. 0 rito não pode ser autoadministrado, pois ele necessita de autoridade superior, seja da Igreja do Estado ou 
representante leigo do poder relativo ao evento, com legitimidade de transmitir o capital cultural, como uma magia, que nomeia oficialmente e em público o título obtido ${ }^{10}$.

Aquelas autoridades passaram a ser testemunhas oculares do poder investido às formandas. Cabe destacar, porém, que, apesar de em ambas as formaturas, a presença de autoridades ter sido registrada, a expressão simbólica da formatura da Escola de Enfermeiras do Departamento Nacional de Saúde Pública se distinguiu da Escola Prática de Enfermeiras da Cruz Vermelha Brasileira, seja pela qualidade das autoridades ou pelo espaço geográfico da formatura.

0 espaço utilizado no rito pela Escola de Enfermeiras do Departamento Nacional de Saúde Pública foi o Instituto Nacional de Música, e pela Escola Prática de Enfermeiras da Cruz Vermelha Brasileira, o pátio externo da instituição. A distinção entre os espaços se refere ao efeito de lugar ${ }^{11}$, que demonstra prestígio e poder. Depreendemos daí que a Escola de Enfermeiras do Departamento Nacional de Saúde Pública à época teve a oportunidade, na formatura, de mostrar à sociedade o potencial do capital simbólico pelo poder e prestígio do efeito de lugar.

Nos ritos de formatura, o momento de juramento foi comum para as escolas de enfermeiras. As formandas da Escola Prática de Enfermeiras da Cruz Vermelha Brasileira juraram perante o símbolo da instituição, conforme consta no conteúdo da revista Brazil-Medico (1924) ${ }^{12}$. As formandas da Escola de Enfermeiras do Departamento Nacional de Saúde Pública juraram conservar a fé na profissão ${ }^{3}$. Depreendemos que as enfermeiras da Escola de Enfermeiras do Departamento Nacional de Saúde Pública estavam mais ligadas entre si pela profissão de enfermagem, em comparação com as formandas da Cruz Vermelha Brasileira, como se revela no momento do juramento.

0 significado do juramento é de ir contra o risco de ruptura e de liberdade, por meio de um contrato tácito, que pode ser entendido como a ditadura do grupo sobre cada um, na presença das autoridades presentes, para lograr o seu objetivo ${ }^{3}$. Este significado dá sentido ao juramento das formandas da Escola de Enfermeiras do Departamento Nacional de Pública, envolvidas com a Reforma Sanitária e a profissão expressada em outros textos fotográficos ${ }^{13}$, diferenciado do juramento das formandas da Escola Prática de Enfermeiras da Cruz Vermelha Brasileira, que juravam em prol da instituição.

Ainda no momento do juramento, destacamos a hexis corporal ${ }^{4}$ das formandas, que somente é possível de ser visualizada por meio da Foto 1, no rito de formatura da Escola Prática de Enfermeiras da Cruz Vermelha Brasileira.

A hexis corporal das formandas foi de perfilamento com o braço direito erguido para frente ao pronunciarem o juramento, a mesma posição adotada pelos militares ao jurarem a bandeira nacional ${ }^{3}$. Compreendemos que essa hexis corporal é uma postura corporal de respeito, o que faz reportar, por exemplo, à posição de joelhos quando se reza. Em outras palavras, pode ser entendida também como o habitus ${ }^{14}$ adquirido para cada tipo de rito.

Foto 1 - Enfermeiras da Cruz Vermelha no momento do juramento(7).

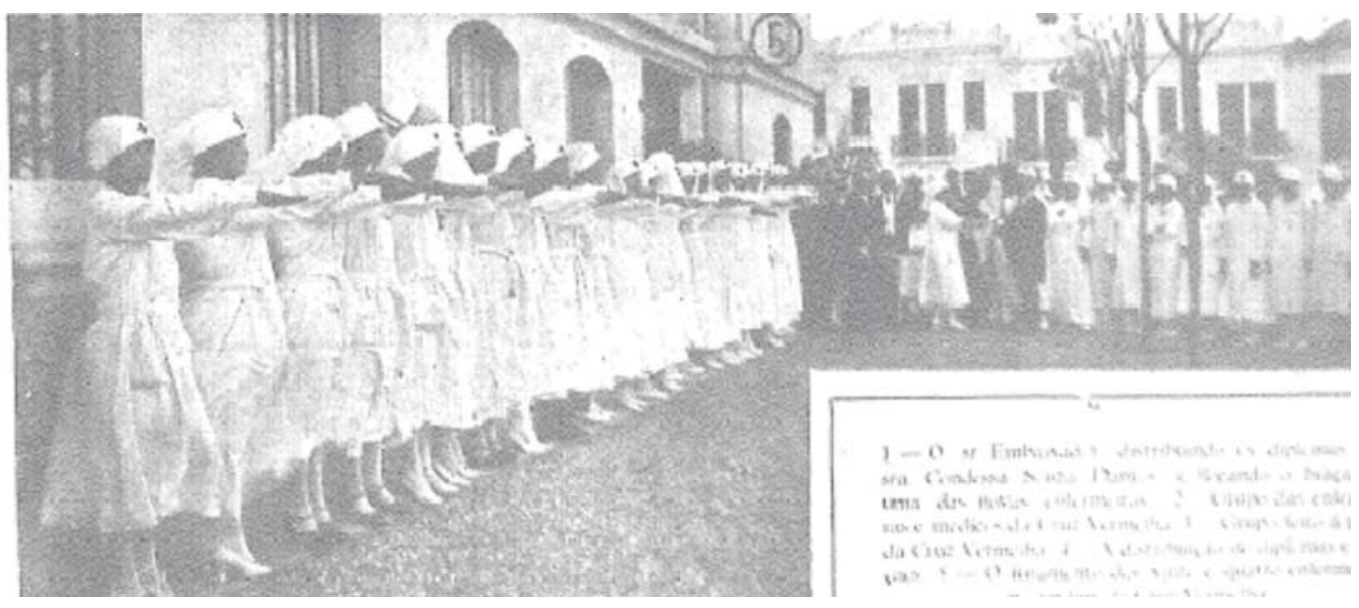

A Foto 1, de tipo irregular, flagra, em ambiente externo, 28 pessoas dispostas em forma de "v" invertido; na legenda, "0 juramento das 24 enfermeiras no jardim da Cruz Vermelha".

Mesmo pela ausência de fotos das formandas da Escola de Enfermeiras do Departamento Nacional de Saúde Pública na Revista da Semana no momento do juramento, inferimos que as formandas também se encontravam na mesma hexis corporal das formandas da Escola Prática de Enfermeiras da Cruz Vermelha Brasileira no momento do juramento, em virtude do habitus ritualístico. 
Foto 2 - Enfermeiras da Cruz Vermelha Brasileira (RJ) com autoridades presentes no momento após o rito de formatura ${ }^{7}$.

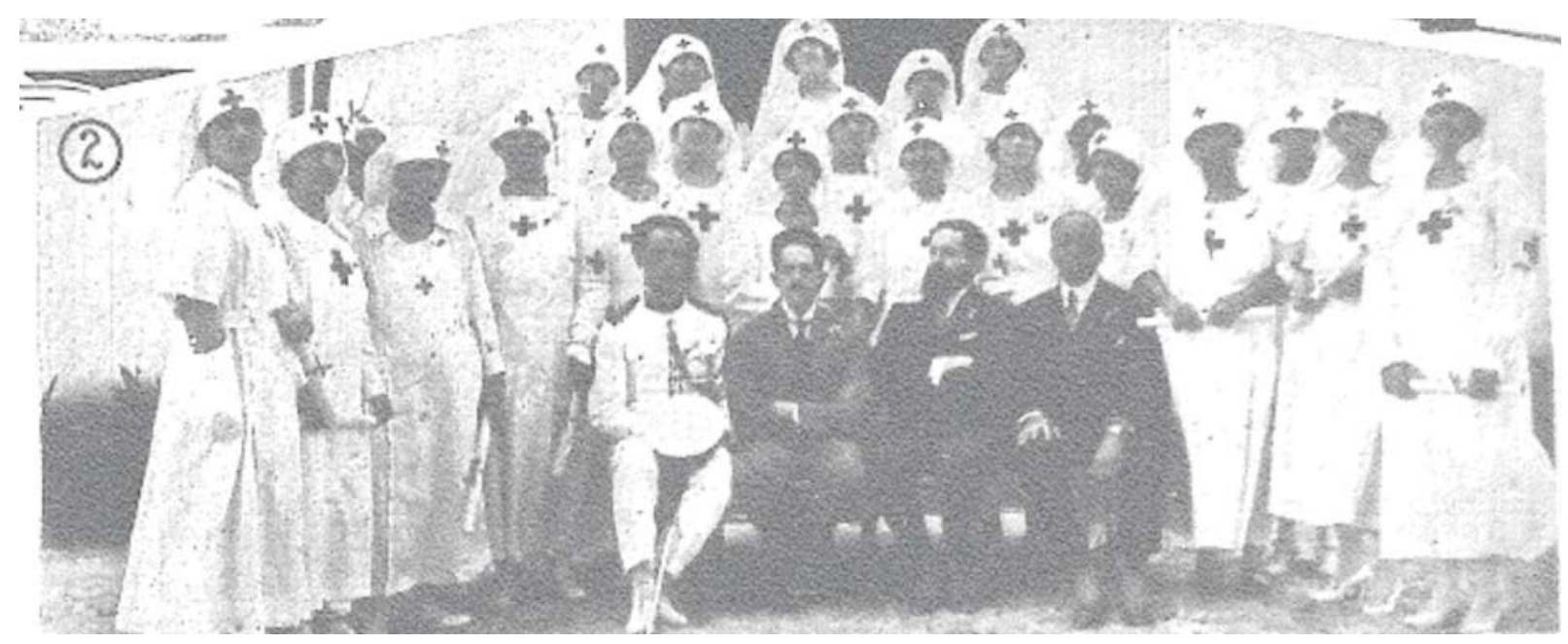

$\mathrm{Na}$ Foto 2, de tipo regular, em ambiente externo, estão 25 retratados, entre eles, da esquerda para a direita: Dr. Amury de Medeiros (o segundo); Dr. Estelita Lins (o terceiro) e Dr. Carlos Eugenio Guimarães (o quarto) - professores do curso de enfermeiras. Na legenda, "Grupo de enfermeiras e médicos da Cruz Vermelha".

Nas fotos, as retratadas têm em suas mãos um papel enrolado, que entendemos ser o diploma. 0 diploma, pelo sistema simbólico, traduz a propriedade e as vantagens do reconhecimento do título oficial como capital simbólico ${ }^{4,14}$. Neste sentido, a titulação de enfermeira correspondia à responsabilidade pela propriedade que o diploma oferecia pelo reconhecimento do saber e do fazer.

As enfermeiras de saúde pública também trajavam seus uniformes, que são mostrados na Foto 3 , em espaço interno do Instituto Nacional de Música. Todas elas trajavam toucas, vestidos de cor clara e de mangas compridas e sapatos e meias de cor clara. Afirmamos que todas se encontravam de sapatos e meias de cor clara, de acordo com a consulta a outra foto aqui não apresentada, mas que está na sequência de fotos mostradas pela Revista da Semana sobre o rito de formatura.

Foto 3 - Enfermeiras de saúde pública no interior do Instituto Nacional de Música9.

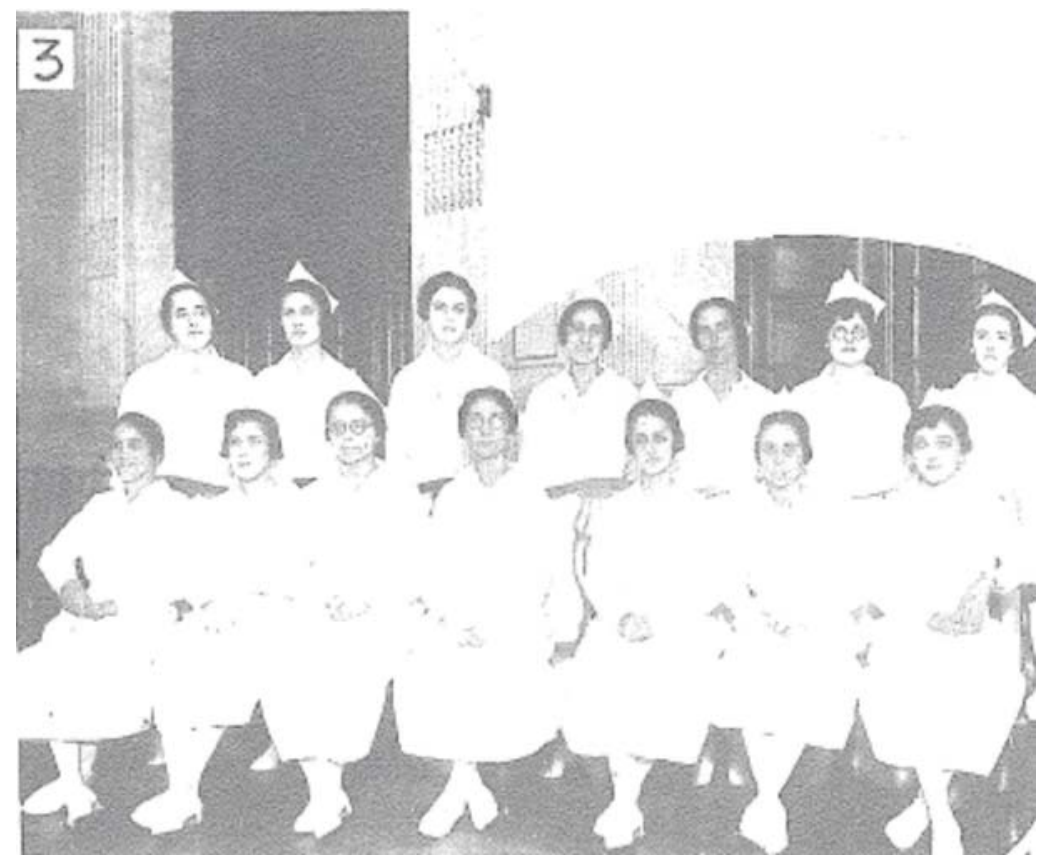


A Foto 3, de tipo irregular, mostra 14 enfermeiras em ambiente interno (Instituto Nacional de Música); entre elas, de pé, da esquerda para a direita: Dulce Macedo Soares (a primeira), Olga Salinas (a terceira), Zulema Lima Castro (a quarta) e Isaura Barbosa Lima (a quinta); e sentadas, da esquerda para a direita, Maria do Carmo Ribeiro (a primeira); Lais Neto dos Reys (a terceira); Josefina Brito (a quarta); Maria de Castro Pamphiro (a quinta); Heloisa Veloso (a sexta) e Noélia Costa (a sétima). Na legenda, "Grupo de enfermeiras diplomadas no Instituto Nacional de Música".

Em ambos os ritos de formatura, as formandas trajavam seus respectivos uniformes. As enfermeiras da Cruz Vermelha trajavam na Foto 2: véu; braçal; vestido, alguns de mangas curtas, outros compridos; sapatos e meias claros; véu; braçal e, no meio do vestido na altura do tórax, o símbolo da instituição - a cruz. Foram retratadas no pátio externo da instituição.

No uniforme das enfermeiras da Cruz Vermelha, destacamos o véu, o braçal e o símbolo da instituição. 0 véu, como atributo pessoal, pela leitura da moda, significa uma das maneiras de ocultar a identidade ${ }^{(15)}$, o que nos fez reportar à imagem de mulheres com véu, como, por exemplo, as filhas de Maria da religião católica.

Quanto ao poder simbólico, Bourdieu cita que "não há poder simbólico sem uma simbologia do poder" ":63. Assim, 0 braçal, entendido pela Cruz Vermelha Brasileira como uma carta de identidade prevista na regulamentação ${ }^{6}$ da instituição, tem o significado de poder simbólico no sentido de neutralidade em períodos de guerra ou de paz pela Convenção de Genebra.

0 símbolo da cruz na cor vermelha estava associado aos cuidados dos feridos de guerra, conforme orientação da Convenção Internacional de Genebra (1863), após a criação da Cruz Vermelha Internacional. A cor do símbolo foi inspirada nas cores invertidas do pavilhão da Suíça, país de origem do idealizador da instituição - Henri Dunat ${ }^{6}$.

Ao se articularem véu, braçal e símbolo institucional, entendemos que se tratam da assinatura imagética da instituição, que traduz a proposta mental da Cruz Vermelha Brasileira. A proposta mental era a da enfermeira bondosa e caridosa como agente mensageira da imagem da instituição ${ }^{3}$.

As formandas da Escola de Enfermeiras do Departamento Nacional de Saúde Pública trajavam uniforme, destacando o atributo pessoal da touca. Esse atributo pessoal ostentado pelas enfermeiras apresenta significados emblemáticos, transmitindo o significado de espírito de serviço, viver com simplicidade, ser modesta, amar a todos igualmente, ser econômica, ser generosa e ser capaz de agir dentro dos princípios éticos e científicos com coerência entre o fazer e o saber, em prol da modernização da profissão. 0 significado está na ética regida pelo ideal nobre e fim superior e se destaca por ser ostentado no centro nobre do corpo humano, a cabeça ${ }^{3}$.

0 significado da touca pode ser encontrado por meio da ética e da modernidade, no sentido de investimento na enfermagem moderna. Esse símbolo ensejava, à época, ser a marca da instituição e, por que não afirmar, para além dela, na criação da crença simbólica pela Enfermagem moderna ${ }^{3}$.

A hexis corporal, no sentido da postura corporal das enfermeiras de saúde pública sentadas, salta aos olhos na Foto 3. As sete retratadas se encontram sentadas, com as mãos apostas sobre as coxas e com os pés cruzados, o que representa o habitus de domesticação do corpo pela economia dos gestos ${ }^{3}$. Esse habituscareceu de evidência da hexiscorporal das enfermeiras da Cruz Vermelha, quando comparadas as Fotos 2 e 3, por serem fotos posadas, o que nos levou a entender ser mais uma marca simbólica, além da touca, de distinção pela formação do habitus das escolas de enfermeiras.

Cabe destacar que, nas fotos veiculadas na Revista da Semana sobre a formatura, não foi possível visualizar a representação objetal do broche na matéria jornalística. Entendemos que o broche usado pelas enfermeiras de saúde pública também tem o mesmo sentido de poder simbólico já mencionado anteriormente, como o braçal das enfermeiras da Cruz Vermelha Brasileira.

Os elementos simbólicos véu e braçal, como o símbolo da cruz e a touca, mostrados pelas fotografias na Revista da Semana, cada um deles marcou a época como assinatura imagética em seus respectivos panteões das instituições envolvidas.

Nos ritos de formatura, por ambas as escolas de enfermeiras, as marcas simbólicas se convergem parcialmente até o momento. Então, partimos para as tradições inventadas ${ }^{16}$, que distinguem os ritos de formaturas pelas escolas de enfermagem.

A tradição inventada é entendida como um conjunto de práticas reguladas pelas regras tácitas, de natureza simbólica ou ritualística, do processo de formalização e ritualização, mesmo que imposta pela repetição ${ }^{16}$. Temos o hino da enfermeira e a passagem da lâmpada ocorrida no rito de formatura da Escola de Enfermeiras do Departamento Nacional de Saúde Pública ${ }^{17}$.

0 hino da enfermeira foi entoado no início do rito de formatura das enfermeiras de saúde pública a fim de proclamar a identidade ${ }^{16}$ profissional da enfermeira. Ademais, o hino, de autoria do compositor Eduardo Souto, com os versos da poetisa Patrícia Eugenia Celso, enunciava os atributos femininos da enfermeira, entendido também como uma estratégia para legitimar a saída da mulher para o trabalho, situação que à época ocorria em paralelo ao sufrágio feminino, para ratificar o poder simbólico da instituição que se encontrava no início da implantação da enfermagem moderna ${ }^{17}$.

A passagem da lâmpada, do tipo grega, foi outro momento do rito de formatura que a Escola de Enfermeiras do Departamento Nacional de Saúde Pública apresentou no investimento simbólico da implantação da Enfermagem moderna no país, apresentada à sociedade pela primeira vez. A lâmpada passou de mão em mão, e, ao final, a formanda Rímidia Gayoso a passou para a aspirante a enfermeira Isolyna 
Saldanha de Lossio, da turma anterior. 0 significado da transmissão da lâmpada foi de revitalização à memória de Florence Nightingale, precursora da Enfermagem moderna ${ }^{3}$.

0 hino da enfermeira e a passagem da lâmpada, momentos exclusivos do rito de formatura à época da Escola de Enfermeiras do Departamento Nacional de Saúde Pública, apesar de carecerem de registro fotográfico na Revista da Semana, podem ser entendidos como formas do sistema simbólico de distinção para a implantação da Enfermagem moderna no país.

0 rito de formatura, por aproximação das expressões de rituais de revitalização e de intensificação, é entendido como renovação de compromisso para as motivações e valorização ${ }^{18}$, motivo pelo qual o estudo o considerou como aglutinação de vários microrrituais.

Neste sentido, os microrrituais se referem ao rito de passagem, sendo uma das formas de negociação de um novo estatuto no seio da sociedade como um sistema simbólico estruturado e hierarquizado de posições associadas de grupos e princípios com a finalidade de produzir distâncias sociais, porém, sem nivelamento. ${ }^{3}$ Depreendemos disso que os ritos de formaturas entre as escolas de enfermeiras, mediante a estrutura dos microrrituais, ao mesmo tempo em que se aproximavam pelo desenvolvimento da profissão enfermagem, por outro lado não as nivelavam pelo capital simbólico.

Desse modo, os microrrituais eram elementos do rito de formatura entendido como rito de passagem, que traduzimos como o poder de impor uma visão das divisões ao torná-lo visível às divisões sociais e políticas por excelência, no sentido de fazer grupos e manipular a estrutura objetiva da sociedade 4 . Em outras palavras, as formaturas das escolas de enfermeiras faziam coisas por meio das palavras e das representações objetais, cada uma produzindo sentido de sua crença simbólica, mas comum entre si pelo desenvolvimento da profissão de Enfermagem no país.

\section{CONSIDERAÇÕES FINAIS}

Os ritos de formatura das escolas de enfermeiras foram publicados na Revista da Semana, possibilitando sua contribuição para a construção da imagem da enfermeira brasileira.

As fotos das enfermeiras no rito de formatura, ao serem publicadas em uma revista de público-alvo feminino, deram visibilidade àquelas agentes sociais durante a Reforma Sanitária, liderada por Carlos Chagas.

As representações objetais também contribuíam para a publicação da imagem da enfermeira como parte integrante do rito institucional. Dentre essas representações, o véu, o símbolo da cruz e a touca foram marcas simbólicas fortes que produziam a crença simbólica de cada escola de enfermeira.

Podemos ao final considerar que os ritos institucionais e as reapresentações objetais utilizados pela Escola Prática da Cruz Vermelha Brasileira e pela Escola de Enfermeiras do Departamento Nacional de Saúde Pública foram estratégias de proclamarem a identidade da profissão, cada qual a sua maneira.

\section{REFERÊNCIAS}

1 - Santos TBE, Porto F, Moreira A Os enfermeiros (as) da Escola Profissional de Enfermeiros e Enfermeiras do Hospício Nacional de Alienados (1906): atual Escola de Enfermagem Alfredo Pinto.

[trabalho de conclusão de curso]. Rio de Janeiro (RJ): Escola de

Enfermagem Alfredo Pinto/UNIRI0; 2004.

2 -. A cerimônia inaugural da sede da Cruz Vermelha Brasileira.

Gazeta de Notícias (Rio de Janeiro) 1917 maio 05.

3 - Porto F, Santos TCF. A enfermeira brasileira na mira do clik fotográfico. In: Porto F, Amorim W, organizadores. História da Enfermagem Brasileira: lutas, ritos e emblemas. $1^{\text {a }}$ ed. Rio de Janeiro (RJ): Águia Dourada; 2008.

4 - Bourdieu P. A economia das trocas simbólicas: o que falar quer dizer. São Paulo (SP): EDUSP; 1998.

5 - Pereira Neto AF. Ser médico no Brasil - o presente e o passado. Rio de Janeiro (RJ) FIOCRUZ; 2001.

6 - Cruz Vermelha Brasileira. Histórico da Cruz Vermelha Brasileira (1908-1923). Rio de Janeiro (RJ): Órgão Central. Cruz Vermelha; 1923.

7 - Na Cruz Vermelha Brasileira. Revista da Semana (Rio de Janeiro) 1924; 25(51): 28.

8 - Carvalho AC. Associação Brasileira de Enfermagem: 1926-

1976- Documentário Brasília (DF): 1976.

9 As novas enfermeiras da saúde pública. Revista da Semana (Rio de Janeiro); 26(27): 28.

10. Bourdieu P. Razões práticas: sobre a teoria da ação. São Paulo (SP): Papirus; 1996.

11. Bourdieu P. Efeitos de lugar. In: Bourdieu P, organizador. A miséria do mundo. Petrópolis (RJ): Vozes; 1997.

12. Cruz Vermelha. Revista Brazil-Medico (Rio de Janeiro) 1924; XXVIII (22): 344.

13 - Santos TCF, Barreira IA, Sauthier J. A fotografia como fonte primária na pesquisa em história da enfermagem. Esc Anna Nery Rev Enferm 1999 abr: 3(1): 72-84.

14 - Bourdieu P. Coisas ditas. São Paulo (SP): Brasiliense; 2004.

15 - Lurie A. A linguagem das roupas. Rio de Janeiro (RJ): Rocco; 1997.

16 - Hobsbawn E, Ranger T. A invenção das tradições. São Paulo (SP): Paz e Terra; 1997.

17 - Santos TCF, Lopes GTL, Fonte AS, Ferreira CL. 0 hino da enfermeira e a proclamação de sua identidade. Anais do $1^{\circ}$ Simpósio lbero-americano de História da Enfermagem [CDROM]. São Paulo (SP): Escola de Enfermagem / USP.

18 - Silva Júnior OC. PAN - Padrão Anna Nery: a instituição da identidade profissional da enfermeira no Brasil. [tese de doutorado]. Escola de Enfermagem Anna Nery/UFRJ; 2000. 